\title{
DENUNCIA Y CONFLICTIVIDAD EN EL MARCO DE AFIRMACIÓN DEL PRINCIPIO DE PROPIEDAD PRIVADA. EL CASO DE LA COLONIA SAN CARLOS Y LAS ESTANCIAS CIRCUNDANTES. 1858-1870.
}

\author{
JOSÉ MIGUEL LARKER (CESIL, FHUC - UNL/ FTS - UNER) \\ Centro de Estudios Sociales Interdisciplinarios del Litoral \\ Facultad de Humanidades y Ciencias - Universidad Nacional del Litoral \\ Ciudad Universitaria - Paraje "EL Pozo"- Santa Fe- Argentina \\ joselarker@yahoo.com.ar
}

\section{Resumen:}

Durante el proceso de colonización del área Centro-Oeste de la provincia de Santa Fe, Argentina, se fue conformando una estructura social y económica compleja, caracterizada por múltiples formas de conflictividad en el marco del proceso de desarrollo del capitalismo agrario pampeano. Atendiendo a ello y ubicándonos en el campo de lo que se ha denominado "historia social de la justicia", en este artículo se analizan las denuncias y los reclamos que se realizaron por la extracción de leña y paja, como también, por la invasión de ganado en campos sembrados en la zona en que se ubicó la colonia San Carlos durante los años iniciales de su instalación. En forma conjunta, se atiende a las normas que pretendían enmarcar las conductas de las personas y el rol desempeñado por los jueces de paz ante esas situaciones. De esa manera, el trabajo se propone un acercamiento a las formas en que se fueron articulando y confrontando necesidades, acciones, derechos e intereses entre los diferentes sujetos del espacio social en cuestión, así como las posibilidades y los límites del Estado provincial para poder resolverlos y hacer efectivo el principio de propiedad privada.

\section{Palabras Claves:}

Denuncia - Propiedad privada - Jueces de paz - Ley - Conflicto

\begin{abstract}
:
During the colonization process of the centre-west area of the province of Santa Fe, Argentine, a complex social and economical social structure was shaping, which was characterized by multiple forms of controversially framed by the process of development of agrarian capitalism. Beaning that in mind and focusing on the field named as "social history of justice", in this article there is an analysis of the complaints that were done because of wood and straw extraction, as well as the livestock invasion in fields saw in the area which belongs to saw San Carlos Colony. When it started to settle down. Meanwhile, the norms that pretended to frame the behavior of people are looked upon, as well as the roles played by peace judges to deal with these situations. In that way, the work is intended to bring closer differents ways in which needs, actions, rights and interested were joint. Among people belong up to the social area being focused on, as well as the possibilities and the bounds of the Province to solve them and make the principle of private property be claimed out.
\end{abstract}

\section{Keywords:}

Complaint - Private Property - Peace Judges - Law - Conflict 


\title{
DENUNCIA Y CONFLICTIVIDAD EN EL MARCO DE AFIRMACIÓN DEL PRINCIPIO DE PROPIEDAD PRIVADA. EL CASO DE LA COLONIA SAN CARLOS Y LAS ESTANCIAS CIRCUNDANTES. 1858-1870.
}

\author{
JOSÉ MIGUEL LARKER (CESIL, FHUC - UNL/ FTS - UNER) \\ Centro de Estudios Sociales Interdisciplinarios del Litoral \\ Facultad de Humanidades y Ciencias - Universidad Nacional del Litoral \\ Ciudad Universitaria - Paraje "EL Pozo"- Santa Fe- Argentina \\ joselarker@yahoo.com.ar
}

\section{Introducción}

Durante la segunda mitad del siglo XIX el espacio pampeano argentino sufrió un acelerado proceso de modernización que, entre otras cosas, produjo fuertes cambios en la organización social y una expansión sin precedentes de las actividades agropecuarias, posibilitando una articulación económica con Europa basada en la venta de alimentos y materias primas. El proceso se dio en paralelo con la conformación del Estado Nacional y la emergencia de un orden político que se prolongó hasta las primeras décadas del siglo XX. El área de la Provincia de Santa Fe no escapó a dicha transformación. Para ello, desde el gobierno provincial se tomaron una serie de medidas con el propósito de proteger la propiedad privada y los intercambios mercantiles, lo que supuso ajustar las normas y las instancias de representación estatal que aseguraran el ejercicio del control y el disciplinando social. Todo ello, en el marco de las pujas y los intereses particulares que fueron aflorando sobre un trasfondo teñido por las concepciones liberales y burguesas en boga durante la época.

Si bien se han producido importantes trabajos que reflejan los estudios realizados sobre el período ${ }^{1}$ (relativos a la formación del Estado provincial, el proceso de ocupación de tierras, el desarrollo agrario santafesino y los cambios sociales que ello supuso), entendemos que los mismos no agotan los análisis y la necesidad de su profundización. En función de ello, en este artículo nos proponemos centrar la mirada en las formas en que se fue definiendo y asegurando el principio de propiedad privada en el área de colonización del Centro-Oeste santafesino durante los primeros tiempos de existencia de la colonia San Carlos. Particularmente nos interesa analizar los conflictos que se generaron en torno a la extracción de leña y paja en la zona y a la invasión de ganado en campos sembrados de la colonia, ya que en ellos se reflejan los derechos que se reclaman y los intereses que expresan los diferentes sujetos en pugna. Consideramos que atendiendo a la manera en que se fueron resolviendo esas cuestiones nos podremos aproximar de modo más ajustado a la compresión de la dinámica en que se fueron instaurando las concepciones y prácticas basadas sobre los parámetros burgueses. Entendemos que el estudio de

\footnotetext{
1 Algunos de los trabajos que son ejemplo de lo que se está diciendo son: Bonaudo, Marta y Sonzogni, Elida, "Viejos y nuevos colonos. Su convergencia en un mundo en transición”, Ruralia, Revista Argentina de Estudios Agrarios, núm. 1, Buenos Aires, Imago Mundi, 1990, pp. 7-41; Bonaudo, Marta y Sonzogni, Elida, "Estados, Empresarios y Colonos en pos de un proyecto de desarrollo agrario. (Santa Fe, segunda mitad del Siglo XIX)", en Bonaudo, Marta y Pucchiarelli, Alfredo, La Problemática Agraria, Buenos Aires, CEAL, 1993, Tomo II; Bonaudo, Marta y Sonzogni, Elida, "Cuando disciplinar fue ocupar (Santa Fe, 1850-1890)", Mundo Agrario. Revista de Estudios rurales, núm.1, Centro de Estudios Históricos rurales, Universidad Nacional de La Plata, Segundo semestre de 2000, en línea en http://mundoagrarioold.fahce.unlp.edu.ar/nro1/bonaudo.htm, consulta: 20 de febrero de 2001; Gallo, Ezequiel, La Pampa gringa. La colonización agrícola en Santa Fe 1870-1895, Buenos Aires, Edhasa, 2004; Gallo, Ezequiel, "Santa Fe en la segunda mitad del Siglo XIX. Transformaciones en su estructura regional”, en Anuario, núm. 7, Instituto de Investigaciones histórica, Facultad de Filosofía y Letras, UNL, Rosario, 1964.
} 
estos temas servirá para algo más que el conocimiento puntual de casos particulares y permitirá arrojar más luz sobre problemas y cuestiones que se inscriben en los procesos generales de conformación histórica del capitalismo sobre el área pampeana santafesina.

El desarrollo del trabajo demandó la consulta de documentación existente en el Archivo General de la Provincia de Santa Fe, especialmente Notas de los Jueces de Paz y Notas Varias que se encuentran en Archivo de Gobierno, Expedientes Judiciales y el Registro Oficial de la Provincia, entre otros. La exposición se organiza en cuatro partes. Comienza aludiendo al proceso que dio lugar a la instalación de la colonia San Carlos, atendiendo a las bases contractuales y normativas sobre la que se llevó a cabo. Luego se consideran los procedimientos para el aprovisionamiento de los recursos necesarios para la subsistencia y el trabajo que ello supuso durante los primeros años de la colonia. El análisis continúa centrando la atención en el intento que realizaron los colonos para darse una organización municipal y, a partir de esa situación, observar algunas de las motivaciones que impulsaron la iniciativa, así como los posicionamientos de los empresarios y de las autoridades gubernamentales al respecto. En el último apartado se tratan las denunciadas que ponían en evidencia las preocupaciones por hacer efectivos los derechos de propiedad, las normas que se fueron generando y las maneras en que intervinieron las autoridades estatales.

\section{La creación de la colonia San Carlos}

El 20 de mayo de 1857, los representantes de una compaña dedicada a la promoción, captación y traslado de europeos para su instalación en las colonias agrícolas que comenzaban a crearse en algunas provincias argentinas (San José en Entre Ríos, Esperanza en Santa Fe y otros emprendimientos, como los llevados a cabo en la provincia de Corrientes), presentaron a Juan Francisco Seguí, Ministro General de Gobierno de la provincia de Santa Fe, una extensa nota en la que expresaban que

"Estimulados [por la preocupación que el gobierno] ha prestado ahora [en una] más decidida y eficaz protección a las empresas mercantiles e industriales destinadas a fomentar y acrecer las profusas riquezas que la naturaleza le ha concedido con tal admirable prodigalidad; han concebido el proyecto de formar un establecimiento colonial a inmediaciones de esta capital $[\ldots]$ ".

De esa manera, la Sociedad Beck, Herzog y Cía. se decidía a dar un nuevo paso en sus emprendimientos proponiéndose llevar adelante, ellos mismos, actividades de carácter especulativo-inmobiliario. De esta manera pretendían participar de la ocupación de las tierras que el Estado provincial iba ganando al control indígena y comenzaba a ofrecer para su ocupación con inmigrantes. Se trataba de un negocio que con el tiempo se tornó muy lucrativo, tanto para los grupos que se iban constituyendo en dominantes en la provincia como para los especuladores extranjeros en este caso. Gastón Gori explica que quienes controlaban los resortes del poder estatal en la provincia proyectaron la subdivisión de las tierras públicas en grandes extensiones adjudicadas a pocas personas y, por otra parte, auspiciaron la formación de colonias agrícolas con inmigrantes, que fueron ubicadas entre medio de las estancias, incrementando de esa manera el valor de sus tierras ${ }^{3}$.

Solo una semana después de presentada la solicitud, el 26 de mayo de 1857, el gobierno aceptó las bases del convenio que proponía la Sociedad Beck, Herzog y Cía. y el Ministro General quedó autorizado para formalizar el respectivo contrato. Si bien el trámite fue desautorizado por la Legislatura durante el mes de octubre, el 7 de noviembre el cuerpo aprobaba una ley que habilitaba al Poder Ejecutivo para concretarlo.

\footnotetext{
2 La nota completa es reproducida en Gshwind, Juan Jorge, Historia de San Carlos, Santa Fe, Imprenta Oficial de la Provincia de Santa Fe, 1994, Tomo I, pp. 50-51.

${ }^{3}$ Gori, Gastón, Elpan nuestro, Quilmes, Universidad Nacional de Quilmes, 2002 (primera edición 1958), pp. 19 y 20.
} 
El contrato definitivo fue firmado por el gobierno de Santa Fe y la sociedad el 25 de noviembre de 1857. Eran los tiempos en que estaba al frente de la gobernación de Santa Fe Juan Pablo López, hermano del fallecido caudillo de los tiempos rosistas, y presidía la Confederación Argentina Justo José de Urquiza.

El contrato firmado establecía en su Artículo $5^{\circ}$ que la Sociedad no podía enajenar las tierras que se les concedía en propiedad, sino que la única condición era poblarlas con colonos extranjeros o implantar establecimientos industriales, también a base de inmigrantes. En el Artículo $7^{\circ}$ especificaba las garantías y reconocía los derechos de los individuos que se introdujeran en virtud del contrato, para lo cual se aseguraba el goce "de los privilegios concedidos por la Constitución Nacional Argentina, siendo libres del servicio militar activo pero quedando obligados a prestar el servicio municipal que les correspondiera".

Por otro lado, el mismo documento concedía a los colonos el derecho de cortar leña y tomar madera de los montes vecinos a la colonia que estuviera en tierras fiscales, sin tener que pagar nada a cambio. Además, el gobierno se comprometía ante la Sociedad Beck, Herzog y Cía. a brindar el apoyo de la justicia y de la policía para mantener el orden en la colonia cuando ellos lo reclamaran, "así como para hacer cumplir a los colonos las obligaciones contraídas con la sociedad colonizadora".

Las tierras fiscales que fueron otorgadas para instalar la colonia debían abarcar una superficie de veinte leguas. Estaban situadas a unos cincuenta kilómetros de la ciudad de Santa Fe en dirección sudoeste. Como ya se ha señalado, la rodeaban estancias, terrenos fiscales y otros pertenecientes a los colonos de Esperanza y al poblado indígena de El Sauce. Así limitaban con la colonia las propiedades de Ricardo Foster, Patricio Cullen, Sañudo, Iriondo, Nicasio Maciel y Sa Pereira, es decir, miembros de los grupos de poder en Santa Fe.

Durante el mes de agosto de 1858 comenzaron las primeras obras en el lugar. Un representante de la empresa llegó al terreno con algunos peones, víveres, ganado, útiles de labranza y semillas, entre otras cosas, y se inició la construcción de los primeros ranchos. Mientras tanto, desde su sede de Basilea, otros se encargaban de reunir familias para trasladarlas e instalarlas en la colonia. Quienes se sumaban a la propuesta debían firmar un contrato de ocho artículos en el que se estipulaban los derechos y obligaciones que ellos asumirían en su relación con la empresa. Esta se comprometía a entregar a cada familia veinte cuadras de tierra para su cultivo, el material necesario para construir sus viviendas, las herramientas de labranza, las semillas, dos caballos, cuatro bueyes y dos vacas lecheras con sus crías. También los víveres necesarios hasta la primera cosecha. Las familias debían entregar a cambio la tercera parte de sus cosechas durante cinco años y pagar los costos de los insumos provistos por la empresa. Cumplidas estas condiciones y el reglamento creado por la empresa para la colonia, los inmigrantes se convertían en propietarios de las tierras que se les había dado en concesión ${ }^{5}$.

El reglamento que formaba parte de los contratos contenía una serie de disposiciones de carácter civil, comercial y contravencional, como también otras relativas a la educación de los menores, la asistencia a huérfanos y viudas y el ejercicio del culto. En el mismo quedaba establecida la forma en que se debía constituir el tribunal para dirimir los casos y los procedimientos a seguir ${ }^{6}$. No contamos con fuentes que nos permitan conocer su funcionamiento, pero si sabemos que la

\footnotetext{
${ }^{4}$ Contrato de colonización celebrado entre el gobierno y los Sres. Beck y Herzog. Recopilación de documentos de Gastón Gori. Museo Histórico de la Colonia San Carlos.

${ }^{5}$ Contrato de colonización... Como dice Gastón Gori "La empresa Beck Bernard obtuvo veinte leguas, que pasaron a ser de su propiedad con sólo la introducción y establecimiento de cincuenta familias de inmigrantes, que le pagaron todos los gastos de viajes, herramientas y le entregaron el tercio de la cosecha durante cinco años.” Gori, Gastón, El pan nuestro, op. cit., p. 20.

${ }^{6}$ Reglamento de la colonia de San Carlos. Recopilación de documentos de Gastón Gori. Museo Histórico de la Colonia San Carlos.
} 
empresa no disponía de los recursos para ejercer el poder de policía que le permitiera hacer cumplir lo estipulado en el instrumento. Sin embargo, desde la administración se desarrollaron todas las acciones a su alcance para persuadir y lograr que el mismo fuera respetado. Cuando esto no sucedió, se apeló a las instituciones del Estado provincial con el objeto de lograr su intervención ante los comportamientos que no se ajustaban a las reglas acordadas entre la empresa y los colonos o no respetaban las leyes del país. Es por ello que en el año 1859, cuando la colonia fue poblada con las primeras familias, Carlos Beck se dirigió al gobierno solicitando "nombrar un Juez colonial interino agregándole las convenientes atribuciones de policía".

Las autoridades respondieron con la aprobación de la propuesta y desde ese momento los jueces de paz que se sucedieron se constituyeron en la máxima autoridad pública a nivel local. Por las funciones asignadas, estos agentes debieron hacerse cargo de dirimir las disputas y los conflictos en que se vieron involucrados la empresa (mientras existió), los colonos, los estancieros vecinos y el Estado. Esto hacía que los jueces de paz no siempre se encontraran en una posición cómoda. Su carácter de vecinos del lugar, el contacto diario con los demás colonos y las relaciones establecidas con ellos, actuaba como contrapeso en las decisiones que debían tomar.

\section{El aprovisionamiento de los recursos para la vida y el trabajo en la colonia}

Es importante tener en cuenta que la geografía del lugar donde se instaló San Carlos se caracterizaba por formar parte de una extensa llanura, con muy buenas condiciones para el desarrollo de la agricultura, "pero no poseía montes, tan necesarios para las construcciones de ranchos. [...] Apenas sí en la parte norte existían algunos, pero insuficientes para el consumo de los colonos". Vinculado a ello, Gastón Gori señala que:

"cuando Beck exploró los campos, creyó que el suyo abarcaría todos los montes del norte y del este. El error encareció la adquisición y acarreo de leña, pues los vecinos exigían el pago por cortarla en sus campos. Y en una época en que tanto se dependía de los troncos para muchos trabajos, el inconveniente vino a sumarse a la larga serie de dificultades"8.

Por otro lado, los campos vírgenes solo estaban amojonados con estacas de madera que indicaban la extensión de las concesiones y los límites con los terrenos de las estancias vecinas. Para deslindar y dar alguna forma de seguridad ante los avances que con frecuencia hacían yeguarizos y vacunos, se cavaron zanjas y se rodeó los campos con espinillos y cina-cina. Pero eso solo se fue haciendo de manera progresiva y brindaba una protección muy precaria.

En las concesiones que se entregaban a los recién llegados, al menos durante los primeros tiempos, solo podían encontrarse con pastizales. Los colonos, con la colaboración de los peones de la empresa o sin ellos, debieron construir todo. A través del diario de Enrique Vollenweider', el administrador de la colonia, nos enteramos de los trabajos que se realizaban en las concesiones del centro de la colonia, que eran explotadas por la empresa colonizadora y que además, funcionaba como una "granja modelo" y centro de experimentaciones para los colonos. Allí

\footnotetext{
7 Archivo General de la Provincia de Santa Fe. Archivo de Gobierno (En adelante: AGPSF AG), Tomo 18, Sección 12: Solicitudes Varias, Año 1859. En la nota se dice que el número de pobladores era cercano a los cien. Hacia 1864 sumaban 641 y en 1872 llegaron a ser 1492. Era elevado el porcentaje de colonos de religión protestante.

${ }^{8}$ Gori, Gastón, Colonización Suiza en Argentina, Santa Fe, Librería y Editorial Colmegna, 1947, p. 29.

${ }^{9}$ Gori, Gastón, Diario del colonizador Enrique Vollenweider, Santa Fe, Universidad Nacional del Litoral, 1858. La obra reproduce los apuntes que Enrique Vollenweider realizó en un diario entre el 1 de febrero de 1860 y el 31 de junio de 1864.
} 
trabajan peones contratados por la empresa y colonos que adeudaban días de trabajo ${ }^{10}$. Así podemos saber, entre otras cosas, que el 6 de febrero de 1860 se produjo la

"Entrada de un peón, Jacob Kaiser, quien llegó a ésta con la familia Stetler a la que se le asignó su concesión y fueron comprados por intermedio de Sixto siete novillos para abasto. La administración continúa la visita regular a las familias de la colonia"11.

En este caso, nos enteramos del arribo de una persona que va a trabajar como peón y de una familia europea que es ubicada en la concesión que le han asignado, de la provisión de animales que serán destinados a la alimentación de la familia y del control que la empresa realiza a los que se van incorporando a la colonia. Pero a lo largo de la sucinta exposición que día a día va registrando Vollenweider también sabemos que el 8 de febrero de 1860 Ramón Freyre vendió ganado para repartir entre las familias, que el 13 febrero una parte de los peones fue mandado a cortar paja a un lugar distante tres horas de la localidad para techar algunos ranchos y que el 20 del mismo mes fueron al monte a buscar leña para quemar, mientras que otros cavaron una zanja alrededor de la granja modelo ${ }^{12}$. El recorrido a través de la información que a lo largo de cuatro años nos ha dejado Vollenweider nos permite observar la reiteración de ese tipo de tareas ${ }^{13}$.

Ahora bien, en función de lo que aquí nos interesa, es necesario preguntarnos sobre el origen de los materiales y animales que se llevan a la colonia. Respecto de ello, el diario de Enrique Vollenweider da cuenta de algunos de los lugares de donde provenían y las formas en que eran adquiridos. Sin embargo, son pocas las especificaciones que realiza y además, solo se registra lo que a la empresa le interesa y/o administra directamente. En función de ello, sabemos que gran parte de los víveres eran adquiridos en el paraje de Maciel, ubicado hacia el sureste de la colonia, antes de llegar a Coronda y sobre el río del mismo nombre. Sabemos que un tal Ramón Freyre vendió durante los primeros tiempos el ganado que era utilizado para el abasto y se carneaba en la granja modelo para repartir entre las familias, como así también el que se entregaba a cada concesión cumpliendo de esa manera con lo estipulado en los contratos firmados entre la empresa colonizadora y los colonos. Según dice Vollenweider, todos los animales estaban marcados, lo que daba cuenta que conocían la propiedad de quien los vendía, aunque nada decía sobre certificados firmados por las autoridades que debían acompañar y dar legalidad al negocio. Por último, las anotaciones nos permiten saber que la paja y la madera que utilizan en la construcción de los ranchos y potreros eran tomadas de los bañados que se hallaban en la estancia de Sa Pereyra, lindante al este de la colonia. Sin embargo, nada dice sobre la leña y paja que se extraía de los campos propiedad de José Rodríguez, en el límite sureste ${ }^{14}$ y de los otros

\footnotetext{
${ }^{10}$ Gori, Gastón, Diario del colonizador..., op. cit., p. 11. Cuando un colono solicitaba a la empresa peones para trabajar en su concesión, este debía devolver a la administración los días trabajados por aquellos desarrollando las tareas que le solicitaran en la granja modelo.

${ }^{11}$ Gori, Gastón, Diario del colonizador..., op. cit., p. 22.

12 Gori, Gastón, Diario del colonizador..., op. cit., pp. 22 y 23.

13 Aquí solo atendemos a algunas de tareas que quedaron registradas, seleccionando solo aquellas que refieren a lo que es materia de interés en este trabajo.

${ }^{14}$ Sobre lo que estamos exponiendo, el diario de Enrique Vollenweider dice: "Febrero 21. Se remiten cuatro carros a Maciel a traer víveres. Se mandan peones a cortar paja para los ranchos de las familias. Por las prolongadas lluvias se llenaron de agua los bañados próximos a Saapereira, tanto que fue, imposible obtener toda la paja necesaria, por lo que tuvimos que buscar otro lugar donde obtenerla por lo cual nos sale más costoso y la calidad deja mucho que desear.

"Febrero 22. Dos peones cortan paja. Los carros vuelven de Maciel, pues las lluvias continuas impidieron cargar. Los otros cortan adobe, Sixto con dos peones trajo vacas y bueyes para las familias. Llega correspondencia de Europa despachada allí los primeros días de diciembre pasado. Entrada de un peón, Eugenio Barbero, en la administración. "Febrero 23. Ramón Freyre entregó dieciocho caballos, veintidós vacas lechera dieciséis bueyes y diez novillos para abasto; todo este ganado está marcado y en su mayoría repartido a las familias de la colonia. Dos peones se envían a Maciel a traer materiales. Dos cortan paja, los otros cortan adobes. A la familia Gogniat se entrega material de construcción. Por las continuas lluvias perdimos alrededor de dos mil adobes.
} 
lugares donde se realizaban esas tareas. Como veremos, la extracción de esos materiales de las estancias vecinas generó una serie de conflictos que derivó en denuncias y solicitudes a las autoridades políticas y judiciales.

\section{El intento de darse una organización municipal para resolver los problemas compartidos}

En febrero de 1862 algunos colonos iniciaron acciones para impulsar la creación de "un cuerpo municipal". Con ese objetivo distribuyeron una nota en la que invitaban a los vecinos a participar de una reunión en la que se trataría el proyecto de crear "una autoridad protectora de los intereses de los colonos". Entre los fundamentes se decía:

"Muchas cosas faltan a la colonia. Falta un culto para cada religión. Falta la instrucción en cada idioma; los hijos de los colonos no pueden se criados como salvajes.

"Precisaremos un monte, pues no creemos que se haya querido establecer una colonia sin darle un monte en propiedad. Además los agentes que nos han contratado nos han dicho que había leña en abundancia. Entonces nos hará falta una ley de bosques para reglamentar su explotación"”.

Como se observa, los planteos referían a carencias y necesidades de diverso tipo, pero lo que aquí debe destacarse es que una de las demandas planteaba la inexistencia de un monte en donde proveerse de leña y madera. Esta era una cuestión que generaba trastornos a los colonos porque al no contar con él debían emplear tiempo y esfuerzos para procurárselo en zonas alejadas, de propiedad fiscal o de lugares en los que contaban con autorización para hacerlo. Claro está que también podían obtenerlo en los campos vecinos, pero esto significaba cometer un delito, a menos que previamente acordasen los términos de la extracción de los materiales con sus propietarios.

Por otro lado, la nota que estamos citando aquí planteaba la falta de una "policía interior" y de una "milicia nacional" que tuviera la función de "defender nuestra propiedad, fruto de nuestro trabajo" ". La necesidad de organizar dicha fuerza podía responder a cuestiones que los colonos percibían como atentatorias de su propiedad y su trabajo y que nosotros desconocemos. Pero no caben dudas que en gran medida esa necesidad respondía a las frecuentes entradas de ganado, pertenecientes a los estancieros vecinos y a los mismos colonos, en los campos sembrados y las consecuentes pérdidas que ello ocasionaba.

La comisión propuso un reglamento para el funcionamiento de la municipalidad y una ley para la elección de sus miembros. Sobre la base del marco normativo creado por ellos mismos, se reunieron el domingo 9 de febrero de 1862, en un número que rondó los cincuenta, y eligieron las autoridades. Todo este proceso fue desaprobado por el Juez de Paz de la colonia y por los responsables de la Compañía Colonizadora. Éstos mandaron notas al gobierno provincial solicitando su intervención para dejar sin efecto lo actuado. Para Beck, Herzog y Cía. se trataba de una "flagrante violación de las leyes vigentes y del orden establecido [...] sin autorización del Exmo. Gobierno y sin arreglo de las leyes del país [...]"17. Según la interpretación que hacían de los acontecimientos, lo que se buscaba era "echar abajo al juez de paz y a la administración para deshacer así del cumplimiento de sus compromisos". Entendían que los deseos de los colonos ya estaban cumplidos y sostenían que:

"Julio 20. Cuatro peones van al monte a traer leña para quemar. Dos peones fueron mandados a recibir el tercio de las familias. Tres trabajan en lo de kappeler, cosechan batatas." En Gori, Gastón, Diario del colonizador..., op. cit., pp. 23 y 35 .

${ }^{15}$ Citado en Gschwind, Juan Jorge, Historia de San Carlos, op. cit., p. 139.

${ }^{16}$ Gschwind, Juan Jorge, Historia de San Carlos, op. cit., p. 140.

${ }_{17}$ Gschwind, Juan Jorge, Historia de San Carlos, op. cit., p. 143. Nota dirigida por Beck, Herzog y Cía. al gobierno de la Provincia el 10 de febrero de 1862. 
"Cuando la administración de la colonia habrá cumplido su mandato, seremos los primeros en pedir al Exmo. Gobierno de la Provincia que se sirva dotar a la colonia San Carlos de instituciones municipales como lo ha hecho recién la colonia Esperanza. Pero no ha llegado aún el momento de tomar semejante medida. Los colonos tienen todavía que cumplir con los compromisos de sus contratos para llegar a ser dueños de sus concesiones. Por ahora no lo son y por consecuencia la colonia no puede ser constituida en un municipio. Al contrario, hasta el cumplimiento de los contratos no puede ser considerada de otro modo que una propiedad extensiva de un solo dueño, trabajada por numerosos operarios bajo ciertas condiciones" ${ }^{\prime 18}$.

Desde la perspectiva de la compañía colonizadora los colonos no podían constituirse en municipalidad porque no eran propietarios sino "operarios" que tenían que cumplir con el contrato que les permitiría a futuro lograr los títulos de propiedad. Mientras tanto, existía un solo dueño que era la compañía. ${ }^{19}$ Cabe decir que los primeros colonos que accedieron a la propiedad lograron hacerlo cuando, en el transcurso de 1864, cumplieron con los términos del contrato firmado con la empresa colonizadora. Gastón Gori señala que "es un hecho comprobable que no todos los colonizadores fueron dueños de las tierras que se entregaron. Muchos no lograron pagar los dividendos a que estaban sujetos antes que se les otorgara el título de propiedad". Esto generó que una parte de los colonos tuvieran que integrarse a los contingentes que estaban en proceso de formar una nueva colonia. Muchos "permanecieron en el campo sin lograr todas sus aspiraciones y dieron lugar a la formación de un colono sin tierra propia, que trabajaba bajo condiciones regladas por convenios entre particulares" ${ }^{20}$. Gori sostiene que en San Carlos solo obtuvieron título de propiedad libre de hipoteca el 31 por ciento, aproximadamente, entre las familias fundadoras hasta 1860. Los que no lo lograron, pasaron a formar parte de un contingente de agricultores endeudados, que tuvo que trabajar tierras ajenas. Claro está que "se registraron traslados continuos de familias de una colonia a otra y en muchos casos se dirigen definitivamente a la villa o las ciudades" ${ }^{\prime 21}$.

Para el caso de los colonos de San Carlos, sabemos que los factores que impidieron que muchos obtuvieran título de propiedad, que otros tantos debieran abandonar la colonia o que tuvieran que inclinarse a acordar diversas formas de contratos para trabajar en tierras que no le pertenecían, fueron muy variados. Entre ellos cabe citar las malas cosechas, las invasiones de langostas, el incumplimiento del contrato al entregar el tercio de la cosecha a la empresa, la falta de experiencia de los colonos para desempeñarse en el trabajo agrícola, las deudas y las condiciones en que debieron instalarse y desarrollar su vida durante los primeros tiempos.

Por otro lado, la referencia a la organización municipal de Esperanza da cuenta que para el momento en que los sancarlinos estaban intentando crear esa institución, aquellos ya contaban con el organismo. Pero no eran pocas las diferencias en lo que hace a su constitución y funcionamiento. Entre las que más llaman la atención se encuentra, en el caso del diseño que se proponían implementar los colonos de San Carlos, la ausencia del juez de paz presidiendo el consejo municipal. ${ }^{22}$ De acuerdo a la Ley Municipal para los Departamentos de la provincia de

\footnotetext{
${ }^{18}$ Gschwind, Juan Jorge, Historia de San Carlos, op. cit., p. 144.

${ }^{19}$ Conviene tener en cuenta que solo al finalizar los cinco años estipulados en los contratos entre los colonos y la empresa aquellos se convertían en propietarios. Ello implicaba pagar la parte de la cosecha que correspondía y las deudas adquiridas con la empresa.

${ }^{20}$ Gori, Gastón Colonización. Estudio bistórico y social de la colonia Humbolt, Santa Fe, Librería Colmegna, 1948, p. 44.

${ }^{21}$ Gori, Gastón, Colonización. Estudio histórico..., op. cit., p. 46.

${ }^{22}$ Para hacer una comparación en lo que respecta a la organización y atribuciones de ambas municipalidades se puede ver la citada obra de Gschwind, Juan Jorge, Historia de San Carlos, op. cit., pp. 140 a 142 y el Registro Oficial de la Provincia de Santa Fe (RO), Tomo III, año 1859-1862, Santa Fe, Imprenta de "La Revolución", 1889, pp. $354-356$.
} 
$1860^{23}$ y el Reglamento de Policía para Esperanza de 1862 el juez de paz debía estar al frente del organismo municipal y ser el único conducto para comunicarse con las autoridades provinciales.

La intención de organizar la municipalidad sobre la base de una normativa producida por los mismos colonos y el desconocimiento de la autoridad de juez de paz, más los planteos realizados por los administradores de la empresa colonizadora sellaron la suerte de lo que se estaba intentando llevar a cabo. Los colonos elegidos fueron apresados y el intento desbaratado. Los sancarlinos tendrían que esperar a fines de 1864 para contar con su municipalidad.

Más allá de las cuestiones organizativas, las demandas planteadas por los colonos no se resolvieron en lo inmediato. La provisión de leña y madera así como los ingresos de animales de estancias vecinas en los campos sembrados por los colonos seguiría siendo un tema problemático.

\section{La defensa de la propiedad y los frutos del trabajo}

Para abril de 1861 hacía más de dos años que la colonia de San Carlos se iba poblando. Esto significó el incremento del número de colonos y de los recursos que se necesitaban para vivir y trabajar. En ese contexto José Rodríguez, propietario de los terrenos que lindaban al Sur de la colonia, denunciaba ante el gobierno de la provincia los "graves los perjuicios que estoy recibiendo en mi establecimiento de campo, que me causan los pobladores de la colonia de San Carlos, disponiendo a su arbitrio de los montes y paja de mi propiedad" ${ }^{\prime 2}$. En la misma nota, Rodríguez manifestaba que la situación había llegado al extremo de que uno de sus peones se viera amenazado de muerte cuando lo envió a solicitarle a "quienes me hacían daño" que se retiraran del lugar. De esta manera se denunciaba perjuicio y daño sobre la propiedad. En otros términos, Rodríguez estaba planteando que se lo estaba privando del libre derecho de disponer de lo que era suyo y por tanto del interés, utilidad, provecho, ganancia o lucro ${ }^{25}$ que se pudiera obtener de la madera de los montes o de la paja que se llevaban los colonos. Por eso, se dirigía a las autoridades del Estado planteando que:

“[...] como un poseedor no puede ver con calma se violen tan desconsideradamente los derechos naturales y civiles que le asisten, sin poner un pronto remedio, ocurro a V. E. como guardián del derecho y la justicia, pa qe (sic) tomen las medidas que crea convenientes [...]"

Se reconoce a las autoridades del Estado como "guardián del derecho y la justicia" y se solicita que tomen las medidas "que crea convenientes" ante lo que se considera una violación del derecho de propiedad. La constitución provincial de 1856 reconocía en su artículo primero que la provincia se hallaba "sugeta (sic) a la Constitución General del 25 de mayo de 1853" llevaba implícito el reconocimiento de los derechos establecidos en el artículo catorce que planteaba, entre otras cosas, que todos los habitantes de la nación tienen el derecho de "usar y disponer de su propiedad" 27 . Rodríguez esperaba entonces que el Estado, como garante de ese derecho, interviniese. En función de ese reclamo, el jefe del Departamento Central de Policía, Coronel José Basualdo, le ordenó una serie de medidas al juez de paz de San Carlos. Pero antes de pasar a considerar esas medidas, conviene atender a la manera en que José Rodríguez concluía su denuncia. En ella se lee: “[...] esperando con fe las medidas tomadas por V. E. me evitaran

${ }^{23}$ RO, Tomo III, año 1859-1862, pp. 158-161.

24 AGPSF AG, Tomo 21, Notas de los jueces de Paz, Santa Fe Abril 13 de 1861.

25 Sobre el significado jurídico que se le daba a las palabras daño y perjuicio ver Escriche, Joaquin, Diccionario Razonado de legislación y jurisprudencia, París, Librería de Garnier Hermanos, 1869.

${ }^{26}$ Historia de las Instituciones de la Provincia de Santa Fe, Documentos del Tomo I, Tratados, convenciones y Constituciones Santa Fe, Santa Fe, Imprenta Oficial de la provincia de Santa Fe, 1969, p. 154.

27 Constitución de la nación Argentina Disponible en línea en: http://www.biblioteca.jus.gov.ar/constitucionargentina1853.html, consulta: 24 de octubre de 2011. 
hacerme de los medios de que para la defensa de mi persona é (sic) intereses estoy munido, para en los casos en qe (sic) sin ley ni justicia se atente contra ellos [...]"28.

¿Cuáles serían los medios a los que se alude? La ausencia de ley y de justicia estaría indicando a su vez la ausencia de Estado, lo que habilitaría a Rodríguez a hacer uso de su propia fuerza para defender su propiedad. Ante este planteo, el gobierno del Estado provincial tenía que hacerse cargo de la situación y actuar en consecuencia. Es que en el marco del proceso de construcción del Estado-Nación y del Estado provincial que se desarrollaba desde mediados del siglo XIX, que se iba institucionalizando bajo las pautas y valores del orden burgués emergente, se hacía necesario llevar a cabo acciones que garantizaran los derechos civiles reconocidos constitucionalmente a los ciudadanos. Para ello se fueron estableciendo normas y creando las agencias que tuvieran a su cargo la intervención en las situaciones como las que estamos analizando y hacer efectivos los derechos de los potenciales damnificados. Más allá de ello, es también importante tener en cuenta que José Rodríguez no era una persona que desconociera las normas básicas del derecho y las competencias del Estado. Era una figura importante de la política provincial. Se inició como comisario de campaña del Departamento Coronda en 1832 y desarrolló una carrera militar en la que fue escalando posiciones hasta convertirse en teniente coronel graduado en 1852 para luego ser comandante militar del Departamento Coronda y en 1854 jefe de la Frontera Norte. Entre 1852 y 1854 fue jefe de policía en Santa Fe y en 1856 gobernador delegado por algunos meses. También ocupó funciones como diputado provincial y senador $^{29}$.

A la denuncia de José Rodríguez se sumó la de Domingo Sa Pereira y el Jefe del Departamento de Policía de Santa Fe fue encomendado para dirigirse al juez de paz de San Carlos y solicitar la intervención ante los colonos. Como consecuencia, el juez de paz informó al jefe de policía que había "[...] librado las ordenes (sic) correspondientes para prohibir a los habitantes de esta colonia entrar en los campos de los Señores D. Domingo Sa Pereyra y José Rodríguez a sacar leña o paja sin licencia de los dueños"30. El juez de paz, en ejercicio de la autoridad concedida, tenía que intervenir en el asunto para proteger los derechos que se veían afectados. De esa manera, se intentaba que los habitantes de San Carlos se ajustaran a las normas que se imponían desde el gobierno, respetando el orden y la propiedad, de acuerdo a los preceptos liberales imperantes ${ }^{31}$. Pero a la par que tomaba esas medidas, el juez informaba que:

“[...] es verdad que desde el establecimiento de esta colonia, los colonos suelen, como les es indispensable, ir a tomar la leña que precisan en los montes vecinos de la colonia, con que la única excepción del Señor Sa Pereyra, ninguno de los dueños les ha negado hasta este último tiempo. Es de advertir también que la leña que los colonos acostumbran llevar consiste en su mayor parte en ramas secas que hallan en el suelo, y que algunas veces cortan de los árboles, siempre dejando lo que es verde. De este modo el perjuicio que pueden causar a los montes es realmente pequeño si no es más bien una ventaja para ellos: ser así limpiamos de las ramas secas, que no utilizan por nadie otro y que en caso de quemazón todo sirve para aumentar los incendios en los montes y causar de esta manera la destrucción de los arboles vivos que quedan"32.

\footnotetext{
28 AGPSF AG, Tomo 21, Notas de los jueces de Paz, Santa Fe Abril 13 de 1861.

${ }^{29}$ Una breve descripción de su carrera militar y política puede consultarse en Wilde, María Josefa, "Es posible una pedagogía política? Un intento en Santa Fe durante el siglo XIX. El caso del Coronel José Rodríguez", I Jornadas del Desarrollo Urbano y rural en la Antigua Jurisdicción del Departamento San Jerónimo-Coronda, Municipalidad de Coronda, coronda, 1994, tomo II, p. 115.

${ }^{30}$ AGPSF AG, Tomo 21, Notas de los jueces de Paz, Santa Fe Abril 29 de 1861.

${ }^{31}$ Bonaudo, Marta "La ciudadanía en tensión. La experiencia de la justicia de paz y del juicio por jurados en Santa Fe. 1853-1890”, en Avances del Cesor, núm. 1, Rosario, Facultad de Humanidades y Artes, Centro de estudios Sociales Regionales, UNR, 1998, p. 47.

32 AGPSF AG, Tomo 21, Notas de los jueces de Paz, Santa Fe Abril 29 de 1861.
} 
Los argumentos eran un claro intento de minimizar los daños y perjuicios que, en clave burguesa, se estaban cometiendo. No caben dudas que la condición de colono del mismo juez de paz, su carácter de vecino del lugar, el contacto diario con los demás colonos y las relaciones establecidas con ellos, actuaba como contrapeso en las decisiones que debía tomar ${ }^{33}$ y de las posiciones que asumía entre ellos, el Estado y terceros. No se negaba la extracción de leña, se la consideraba "indispensable" y el perjuicio "pequeño". Para más, el juez consideraba una ventaja para los propietarios la acción de limpiar de ramas secas "que no utilizan por nadie otro y que en caso de quemazón todo sirve para aumentar los incendios". De esta manera, lo que para los propietarios de los montes era considerado como acciones de hurto, para el juez de paz se volvía una necesidad que era indispensable satisfacer, a la vez que prevenía posibles pérdidas mayores. Frente a la obligación de acatar la orden dada por las autoridades del gobierno provincial, el juez de paz propuso una alternativa para satisfacer los intereses de las partes:

"Creo Señor jefe que la leña no se puede negar a los colonos y ofrecemos todos, los colonos como la administración pagar a los dueños de los montes un precio equitativo para cada carreta de leña que se saca. Creo también que el Exmo Gobierno de la Provincia debe mirar a la colonia como a un establecimiento de utilidad pública y que en este sentido no nos negará su influencia para con los Dueños de montes fijando a este respecto un arreglo al que nos sometemos de ante mano"34.

Nuevamente se acudía a las autoridades del gobierno para que intercedieran, pero en este caso para poder acordar entre los propietarios de los montes y los colonos "un precio equitativo para cada carreta de leña que se saca". Se reconocía que la leña era propiedad del estanciero y se la solicitaba como mercancía, pero se recurría a la mediación del Estado para poder acordar un precio más favorable a los colonos.

Las fuentes ponen en evidencia que los problemas relativos a la extracción de leña y paja continuaron durante la década de 1860 y parte de la siguiente en esa región de la provincia. Mientras ello sucedía, se designaron policías bajo el mando del juez de paz para posibilitar un mayor control y se fueron elaborando las normativas en torno a lo que se consideran las aristas policiales del problema rural ${ }^{35}$, buscando regular el trabajo, los intercambios y afianzando el principio de propiedad. En 1864 la legislatura aprobó el Reglamento de Policía Urbana y Rural y en 1867 el Código Rural, siendo este una réplica del ya existente en Buenos Aires. Marta Bonaudo y Elida Sonzogni nos explican que estos instrumentos plantean prioridades tanto en el ámbito de la propiedad como en el campo laboral y que una de las intenciones explicitas que observan es "modificar las prácticas consuetudinarias confirmando un único y exclusivo derecho de propiedad asentado sobre parámetros de privacidad y plenitud"36.

Para preservar el derecho de propiedad de tierras y haciendas, el Reglamento y el Código estipulaban con rigurosidad la prohibición de la caza furtiva y las extracciones de los productos espontáneos del suelo ${ }^{37}$. El código rural planteaba:

\footnotetext{
${ }^{33}$ Larker, José Miguel, "Las tareas de la justicia de paz en San Carlos: Actores, conflictividad y orden social. 18591871", VI Jornadas de Sociología de la UNLP, La Plata, 9 y 10 de diciembre de 2010.

34 AGPSF AG, Tomo 21, Notas de los jueces de Paz, Santa Fe Abril 29 de 1861.

35 Wilcken, Guillermo, Las Colonias. Informe sobre el estado actual de las colonias de la República Argentina, Buenos Aires, Imp., Lit., y fundición de tipos a vapor de la Sociedad Anónima, 1873, p.49. Bonaudo, Marta y Sonzogni, Elida, "Cuando disciplinar fue ocupar (Santa Fe, 1850-1890)", op. cit.

${ }^{36}$ Bonaudo, Marta y Sonzogni, Elida, "Cuando disciplinar fue ocupar (Santa Fe, 1850-1890)”, op. cit.

37 Con el objeto de asegurar el principio de propiedad el Reglamento de Policía Urbano y Rural y Código Rural establecían un conjunto de disposiciones mucho más amplio que el que atendemos en este trabajo. Entre ellas se pueden citar como ejemplo las imposiciones a la obligación de los pulperos de justificar la procedencia de cueros por compra o permuta, con los correspondientes certificados o guías; la penalización del el abigeato, ordenando la permanente realización de rodeos para dirimir la propiedad del ganado, asentando la obligación de marcas,
} 
“Artículo 264-La propiedad del junco, totora, pajonal, cardo, biznaga, duraznillo, piedra, conchilla, y demás productos espontáneos o adherencias de la tierra, es del dueño o poseedor de ella y solo con su licencia, o bajo el precio o condiciones que él establezca, pueden ser tomadas o esplotadas (sic) por otro. Lo contrario podrá ser reputado y penado como hurto" 38 .

En la sección séptima del código también quedaba establecido que los productos del tipo que se mencionan en el Artículo $264^{\circ}$ que nacieran o se hallaran en tierra pública (también se incluían los sauzales, bosques y árboles sueltos) pertenecían a la municipalidad o en su falta al juzgado de paz. Se facultaba a la autoridad local para gravar el aprovechamiento de esos productos y para imponer multas o destinar a trabajos públicos a los que se apropiaran de los productos sin ajustarse a lo establecido.

Ante la necesidad de adaptarse a las normas que se fueron imponiendo y los controles de las autoridades estatales, las opciones se redujeron a la adquisición de la leña o la paja por medio de un pago en moneda o su producción en los terrenos de quienes la consumían. En este sentido, el inspector de colonias Guillermo Wilcken describía los cambios que lograron producirse en las concesiones que se convirtieron en propiedad de algunas de las familias que habitaron la colonia. Así por ejemplo, mencionaba el caso de la familia Goestchi y luego de enumerar los animales, la extensión de la tierra cultivada y las construcciones que habían realizado hacia 1863, expresaba que tenían "una plantación floreciente de 1600 duraznos y algunos otros árboles frutales"; la familia Reutemann tenía para el mismo año "un hermoso jardín lleno de flores y una plantación de 3000 duraznos con varios otros árboles". Para 1872 esta misma familia había "agrandado el plantío de árboles frutales y de adorno. También destacaba que todos los muebles de la casa: mesas, aparador, armarios, sillas, \&\& son hechos de madera del Gran Chaco" ${ }^{\text {"39 }}$. En el mismo informe se deja aclarado que no todos los colonos habían logrado esos progresos, pero en base a esos datos Wilcken destacaba los avances logrados en San Carlos hacia 1872 dedicándole un apartado en el que señalaba:

"He aquí una prueba de la previsora inteligencia de los primitivos colonos. Mientras que en la 'Esperanza' y demás colonias, que acabaron con los bosques circunvecinos, se ven obligados á buscar su combustible á 12 leguas de distancia, la de San Carlos tiene en los magníficos bosques de duraznos y demás árboles plantados, á lo menos, el combustible necesario para su propio consumo. En cuanto á madera se la procuran en los montes de Gruetli ó en las selvas marginales del Río Salado, pagando el derecho de corte [...]"40

Si las cuestiones relativas a la obtención de leña y madera se fueron enmarcando en el orden que se fue imponiendo, aunque no sin conflictos, el problema suscitado ante las invasiones de ganado proveniente de las estancias vecinas a los campos sembrados de la colonia continuó durante todo el período ${ }^{41}$. En la misma nota en que el juez de paz informaba del cumplimiento de las órdenes ante la extracción de leña y paja de los campos de Rodríguez y Sa Pereira que hemos citado más arriba, se decía que:

“[...] si el Señor D. Domingo Sa Pereyra se queja de perjuicios que le causa la colonia, la colonia tiene muchos más motivos de quejarse de los perjuicios ingentes que les ha sido causado por el ganado de este Señor.

contramarcas y señales. RO, Tomo IV, Reglamento de Policía Urbana y Rural de la Provincia de Santa Fe, 1864, p. 210-233 y Código Rural de la Provincia de Santa Fe, Santa Fe, Imprenta Nueva Época, 1886.

38 Código Rural..., op. cit., p. 49.

${ }^{39}$ Wilcken, Guillermo Las Colonias..., op. cit., pp. 64 a 67.

${ }^{40}$ Wilcken, Guillermo Las Colonias..., op. cit., p. 53.

${ }^{41}$ Es importante tener en cuenta que las invasiones de ganado a los campos sembrados no solo se produjeron por aquellos que pertenecían a los estancieros vecinos. También hubo casos de animales pertenecientes a los mismos colonos que se internaban en los trigales o maizales de otros causando importantes estragos. Un ejemplo de ello puede verse en AGPSF AG, Tomo 20, Notas de los jueces de Paz, Santa Fe junio 13 de 1860. 
"Muchas veces ya se ha rogado al Señor Sa Pereyra y a sus capataces y peones que tengan la bondad de dirigir al ganado hacia otras partes y no hacia la colonia, pero no se han dejado tomar en consideración nuestra peticiones, al contrario, se dice muchas veces que los peones se han hecho un juego de echar apropósito el ganado en la colonia antes de la noche. La verdad es que casi todas las noches la colonia se ve invadida por tropas de ganado yeguarizo o vacuno, tan fuerte y inmensas que los colonos no son capaces de defender sus sementeras contra ellas".

Para evitar que el trabajo realizado por los colonos sufriera los daños y perjuicios a que refiere la cita, se inició en 1860 la construcción de una zanja "pero no se pudo acabar de una vez y en el intervalo lo que ha sido hecho, ha sido ya muy destruido por el mismo ganado". El daño causado en los sembradíos de trigo, maíz, papa, batata, maní y cebada generaba un gran desaliento en las familias que vivían lindando los campos de Sa Pereira, a tal punto que "[...] una familia especialmente que no ha podido preservar una sola planta desde un año que esta creo y que últimamente se ha desalentado en tal grado que a (sic) abandonado su terreno".

Durante el año 1861 las quejas continuaron y el juez de paz se vio impelido a comunicarse con las autoridades provinciales ante la presión de los colonos que decidieron suspender sus trabajos hasta obtener las garantías contra los daños a que eran expuestas sus sementeras por parte del ganado de los estancieros ${ }^{42}$. Los mismos colonos que eran denunciados por extraer leña y paja de los montes de los campos vecinos, reclamaban por sus derechos de propiedad. En este sentido el juez de paz exponía al ministro de gobierno que

"El mismo Gobierno ha destinado estos campos para ser colonizados y una consecuencia natural del contrato que ha celebrado a este respecto es que la propiedad de los colonos y el fruto de sus trabajos sean garantidos contra los daños causados por animales ajenos y contra cualquiera invasión. También la Constitución de la Confederación Argentina garante a todos los habitantes su propiedad y el libre ejercicio de su industria" ${ }^{\text {"43 }}$.

El juez de paz reclamaba por los derechos de los colonos apelando a los compromisos contractuales que había adquirido el gobierno provincial y a lo establecido en la Constitución Nacional. Más allá de los reclamos, entendía también que era necesario tomar medidas que implicaran cambios para hacer efectivos los derechos y, en ese sentido, entendía

“[...] que la medida más natural y más acertada será declarar tierras de pan llevar a las colonias agrícolas conforme que se vayan poblando, lo que sin duda se podría conseguir en la próxima sesión de la honorable Asamblea legislativa, si al Exmo Gobierno le parece bien introducir semejante propuesta" ${ }^{44}$.

La iniciativa fue recogida por las autoridades del gobierno y el 1 de julio de 1861 se aprobó una ley declarando tierras de pan llevar a los terrenos de la colonia. Con la expresión "tierras de pan llevar", se reconocía que esas tierras eran dedicadas exclusivamente al cultivo de cereales y por tanto, debían ser protegidas de los posibles daños que causaban los animales vacunos o yeguarizos. A partir de la sanción de la ley, las estancias vecinas debían ajustarse a las medidas que estipulaba ya que "la consecuencia de esta ley es que los estancieros son responsables de los perjuicios causados por sus animales y que los puestos de ellos deben ser alejados de la colonia a una distancia de una legua por lo menos"

En los tres años posteriores a la sanción de la ley no se produjeron inconvenientes del tipo que estamos tratando, probablemente porque se cuidó con más celo que los animales no entraran en los sembradíos de los colonos. Pero a mediados de 1864 los sancarlinos volvieron a quejarse.

42 AGPSF AG, Tomo 21, Notas de los jueces de Paz, Santa Fe junio 12 de 1861.

${ }^{43}$ AGPSF AG, Tomo 21, Notas de los jueces de Paz, Santa Fe junio 12 de 1861.

44 AGPSF AG, Tomo 21, Notas de los jueces de Paz, Santa Fe Abril 29 de 1861.

45 AGPSF AG, Tomo 24, Notas de los jueces de Paz, San Carlos 21 de Mayo de 1864. 
Hasta ese momento, los colonos ubicados en la parte sur y suroeste plantearon que no sufrieron daños de la hacienda de las estancias "debido únicamente al mejor cuidado de los capataces y peones porque no se mudó ningún puesto". Según los colonos, las nuevas invasiones se producían como consecuencia del incumplimiento de la ley del 1 de julio de 1861 ya que "el Señor Sa Pereyra tiene un puesto importante a una distancia de pocas cuadras del límite de la colonia". Por eso el reclamo de los colonos concluía solicitando que "el puesto del Señor Sa Pereyra sea mudado a una parte donde no nos perjudique y que la ley del $1^{\circ}$ de Julio de 1861 reciba su entero cumplimiento" ${ }^{\prime 46}$.

Que Domingo Sa Pereira se ajustara a las normas que tanto reclamaban los colonos parece que no fue cosa fácil. No se conoce mucho de este estanciero. Sabemos que vivía en Coronda y maneja sus negocios desde allí y que, además de los campos que poseía al oeste de la colonia San Carlos, había adquirido otros en las proximidades de Rosario, en los terrenos que hoy ocupan las colonias Acebal, la Penca y Villa Emilia. El 27 de julio de 1857 Sa Pereira inició los trámites correspondientes a la compra de los terrenos que eran propiedad del Estado santafesino en la zona lindante con lo que sería la colonia de San Carlos. Es llamativo que el negocio se realizara casi en paralelo con las gestiones que Beck y Herzog estaban haciendo para instalar la colonia. El 6 de agosto de 1857 Ángel De Arrarte, en su calidad de apoderado de Domingo Sa Pereira, pagaba la suma de 3.200 pesos por el terreno que era atravesado por el arroyo Las Saladas. Su extensión era de más de 12 leguas, es decir, unas 30.000 hectáreas ${ }^{47}$. Con esta compra y la posterior valorización con la que se favoreció como producto de la instalación de colonias y los negocios inmobiliarios que se llevaron a cabo, Sa Pereira se consolidó como miembro de los grupos dominantes de Santa Fe.

Desconocemos si el puesto ganadero que generaba problemas a los colonos fue trasladado. Lo ciertos es que por algún tiempo no se volvieron a producir quejas en ese sentido. Entre tanto, como ya se ha mencionado, se sancionaron el Reglamento de Policía y el Código Rural. En el primero, quedaba establecido que

"Art. 83 Los comisarios prohibirán que los hacendados mantengan siempre sus haciendas en agena (sic) propiedad, ya sea por falta de campo o por negligencia, pues todos están obligados a tenerlas sujetas en el radio de campo que les pertenece. Los contraventores pagarán una multa de veinticinco pesos" ${ }^{\$ 8}$.

El instrumento daba facultades a los comisarios y sancionaba a los infractores que "por falta de campo o por negligencia" permitieran que sus ganados se internen en propiedades ajenas. En los artículos correspondientes al rubro "Apartes de Hacienda" se establecían otras prohibiciones (por ejemplo la prohibición de entrar en campos ajenos sin permiso con el pretexto de recoger hacienda) y los procedimientos que debían seguirse para devolver los animales a sus dueños. También se establecía en el Artículo $131^{\circ}$ que los rodeos del ganado debían realizarse a cuatro cuadras del límite del terreno con los de otra propiedad o en el centro si fueran terrenos pequeños.

Con la sanción del Código Rural de la Provincia de Santa Fe se precisaron las normas que establecían los derechos, las obligaciones y las sanciones a que estaban sujetos las propiedades y el trabajo en campo. En lo que respecta a los cuidados que debía tenerse con el ganado el Artículo $10^{\circ}$ decía que "Quien tenga su casa habitación cercana a campo ageno (sic), largará sus

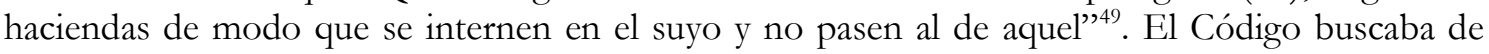

\footnotetext{
46 AGPSF AG, Tomo 24, Notas de los jueces de Paz, San Carlos 21 de Mayo de 1864.

${ }^{47}$ Los datos fueron extraídos de una publicación existente en el Archivo General de la Provincia de Santa Fe y que fuera realizada en conmemoración del centenario de la localidad de Sa Pereira. jSa Pereira, feliz. centenario! s/d, Octubre de 1986.

${ }^{48}$ RO, Tomo IV, Reglamento de Policía Urbana y Rural..., op. cit., p. 224.

${ }^{49}$ Código Rural..., op. cit., p. 6.
} 
esa manera evitar que los animales pasaran a campos vecinos. Cuando ello sucedía, se planteaban procedimientos similares a los del Reglamento de Policía. Pero el Código se ocupa en el Título Segundo de "los terrenos de labranza" y en ellos se excluía la crianza de ganado mayor de toda especie, pudiendo solo hacerse la del ganado menor y la de aquel necesario para las faenas, los trabajos y los de lechería ${ }^{50}$.

La sección Quinta estaba dedicada a “Animales Invasores" y en los Artículos $167^{\circ}$ a $173^{\circ}$ se establecían las atribuciones del juez de paz, los procedimientos y las penalidades que debían aplicarse en cada caso.

La normativa por sí sola no solucionó los problemas de que se quejaban los colonos sancarlinos. Pero se establecieron con claridad los derechos y las obligaciones que debían regir en el campo. De esa manera los jueces de paz contaron con nuevos instrumentos para actuar. No obstante las quejas continuaron y algunas dificultades siguieron subsistiendo. En 1867 el juez de paz de San Carlos se comunicaba con el Ministro General de Gobierno puesto que:

“[...] todos los propietarios de terrenos ubicados a la orilla de esta colonia se presentaron en este Juzgado exponiendo que los animales especialmente yeguarizos de los estancieros limítrofes e inmediatos, les originan continuamente daños y grandes perjuicios pastoreando noche y día en el sembrado e instando para que determine las convenientes medidas al objeto de evitar semejante abuso"

Pero el problema fundamental era que los estancieros estaban domiciliados fuera de la jurisdicción del juez y eso le impedía actuar. Ante las limitaciones, se solicitó al gobierno facultades para "[...] poner fin a un abuso de tanto perjuicio á (sic) muchas familias que solo viven de su trabajo sin más recursos, y a las alegaciones que pueden tener lugar [ante] tan injusto pastoreo" ${ }^{, 2}$. Con las mismas dificultades se encontró el juez de paz Tomás Lubary en noviembre de 1869 cuando Clemente Sañudo, propietario de los campos que lindaban al este de la colonia, le señaló que no tenía facultades para actuar puesto que "no estaba bajo la jurisdicción de este juzgado la prueba notoria que se estaba formando en el campo"53. Sin lugar a dudas, estas limitaciones de las autoridades para poder intervenir en los conflictos generados en torno a la invasión de los campos por animales ajenos, los problemas derivados de los apartes de ganado y la forma de hacerlo, generaron inconvenientes y, en algunas circunstancias, se vieron favorecidos los infractores. En forma paralela, una nueva modalidad de delimitar y proteger los bienes vino a sumarse con la llegada del alambrado. Fue durante esta década de 1860 cuando el elemento y las técnicas de su disposición ${ }^{54}$ comenzaron a implementarse en la zona de las colonias agrícolas. Siguiendo esa tendencia hacia 1872, la familia Goetschi tenía:

“3 concesiones juntas, alambradas del modo más perfecto a un costo de 700 a 800 pesos bolivianos por cada concesión, un hermoso monte de toda especie de árboles frutales plantados y cuidados con esmero. [...] la concesión primitiva está rodeada además del cerco de alambre, con otro de cina-cina, que ha alcanzado una altura asombrosa" ${ }^{35}$.

También la familia de Santiago Reutemann tenía hacia el mismo año 2 3/4 lotes de chacra

\footnotetext{
${ }^{50}$ En el Artículo $151^{\circ}$ expresaba que "todos los partidos existentes fuera de los puntos y superficie señalada, puede continuarse y aun estenderse (sic) el cultivo de la labranza [...] pero no por eso podrá escluirse (sic) de ellos la crianza de ganado mayor". Pero en el artículo 152 se aclaraba que "seguirá escluida (sic) la crianza de ganado mayor de aquellos de dichos departamentos que hoy son esencialmente o principalmente agricultores, como también de aquellas fracciones o porciones de ellos, que ya están formalmente declarados de pan llevar”. Código Rural..., op. cit., pp. 30 y 31. Recordemos que San Carlos era considerada tierra de pan llevar desde 1861.

51 AGPSF AG, Tomo 27, Notas de los jueces de Paz, San Carlos Julio 30 de 1867.

52 AGPSF AG, Tomo 27, Notas de los jueces de Paz, San Carlos Julio 30 de 1867.

53 AGPSF AG, Tomo 29, Notas de los jueces de Paz, San Carlos noviembre 27 de 1869.

${ }^{54}$ Para el caso de la utilización del alambre como medio para cercar los campos es interesante la lectura de Sbarra, Noel H., Historia del alambrado en Argentina, Buenos Aires, editorial Raigal, 1955.

55 Wilcken, Guillermo Las Colonias..., op. cit., p. 65.
} 
perfectamente alambrados. Algo similar sucedía con las concesiones de la familia Sigel: el alambre y la cina-cina las protegían de los posibles embates del ganado ${ }^{56}$. Esto no quiere decir que todas las propiedades de la colonia estuvieran alambras o protegidas con cina-cina, ya que lo que estamos citando son los casos de los colonos más prósperos. Muchos solo podían resguardar sus campos con zanjas, cina-cina o espinillo y otros ni siquiera eso. En las estancias comenzó a darse el mismo proceso ${ }^{57}$.

\section{Conclusión}

La instalación de la colonia San Carlos se realizó en terrenos que el Estado provincial había ganado al control indígena y su localización, en medio de campos vendidos por el gobierno a sujetos que formaban parte de los grupos de poder, permitió la valorización inmobiliaria del área y contribuyó al desarrollo de las actividades de producción e intercambio. Como se ha podido observar, a la vez que avanzó el poblamiento y se pusieron en producción las concesiones, comenzaron a generarse una serie de conflictos, entre los colonos y los estancieros vecinos, relacionados con la extracción de leña y paja y con la invasión que el ganado realizaba a los campos sembrados. Entre las condiciones que los favorecieron, pesó el hecho de que el espacio donde se estableció la colonia no existieran montes que permitieran el aprovisionamiento de materiales indispensables para las construcciones y las necesidades de la vida cotidiana de los colonos, las condiciones materiales en que estos llegaron a la zona y los compromisos contractuales con la empresa colonizadora. Por otro lado, las limitaciones para asegurar y proteger las propiedades, contribuyeron a la generación de situaciones que afectaron los intereses de unos y otros.

Como se ha podido observar, la empresa colonizadora sujetó a los colonos a una reglamentación que pretendía asegurar ciertas formas de comportamiento, trabajo y productividad esperando que ello favoreciera el cumplimiento de los compromisos firmados y el logro de la rentabilidad esperada. Muy pronto se apeló al gobierno para que designara una autoridad con atribuciones de justicia y policía y, a partir de entonces, las disputas se canalizaron a través de la figura del juez de paz. Sobre este funcionario recayó en gran parte la responsabilidad de dirimir los conflictos y mantener el orden según las normas que se fueron estableciendo y las directivas que recibía de las autoridades superiores.

Las fuentes consultadas nos permitieron constatar los problemas que los colonos tenían para proveerse de leña y madera entre otras cuestiones. La misma administración y los jueces de paz reconocían que las extracciones se realizaban de terrenos que no eran propiedad de los colonos o de la misma empresa. Los propietarios denunciaron estas situaciones argumentando los derechos constitucionales que le asistían lo que derivó en la implementación de medidas para impedir las prácticas que afectaban sus intereses. Cuando en 1862 los colonos intentaron darse una organización municipal esgrimieron entre sus argumentos la necesidad de tener un monte y una policía que pueda defender la "propiedad, fruto de nuestro trabajo." La iniciativa no logró llevarse a cabo y los problemas que pusieron al descubierto continuaron sin resolverse en lo inmediato.

En el marco del proceso que durante estos años se desarrolló en la provincia, el agotamiento de los terrenos fiscales por compra o entrega a propietarios particulares fue acompañado del afianzamiento de la propiedad privada. Una de sus consecuencias fue que la obtención de leña y madera solo pudo realizarse a través de su compra en el mercado o produciéndolos en los terrenos de los mismos que harían uso de esos materiales. En lo que respecta a las invasiones que el ganado solía hacer en los campos de cultivo, hubo que esperar hasta que los deslindes de los

56 Wilcken, Guillermo, Las Colonias..., op. cit., pp. 64 a 67.

${ }^{57}$ Para la provincia de Buenos Aires se puede ver el trabajo de Sbarra, Noel H., Historia del alambrado..., op. cit. 
terrenos se realizaran con alambrados para asegurarse de que eso no suceda. En algunas concesiones esto comenzó a practicarse entre fines de los años sesenta y principio de los setenta. Mientras tanto, el gobierno provincial fue ajustando la legislación a los requerimientos que en el ámbito rural se iban produciendo. En 1864 se sancionó el Reglamento de Policía Urbano y Rural y en 1867 el Código Rural. La normativa por sí sola no solucionó los problemas que aquejaban a los colonos sancarlinos, pero se establecieron con claridad los derechos y las obligaciones que debían regir en el campo. De esa manera los jueces de paz contaron con nuevos instrumentos para actuar. A través de ellos, los principios de propiedad se fueron consolidando y asegurando, favoreciendo la instauración plena de las relaciones de tipo capitalista. 